\title{
Ethanol, ethyl and sodium pyruvate decrease the inflammatory responses of human lung epithelial cells via Akt and NF-kB in vitro but have a low impact on hepatocellular cells
}

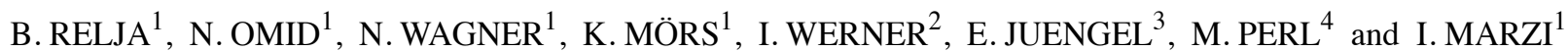 \\ ${ }^{1}$ Department of Trauma, Hand and Reconstructive Surgery, ${ }^{2}$ Department of Thoracic and Cardiovascular Surgery, \\ ${ }^{3}$ Department of Urology and Pediatric Urology, University Hospital Frankfurt, Goethe University Frankfurt am Main, \\ D-60590 Frankfurt; ${ }^{4}$ Department of Trauma Surgery, Trauma Center Murnau, D-82418 Murnau, Germany
}

Received August 11, 2015; Accepted December 2, 2015

DOI: $10.3892 /$ ijmm.2015.2431

\begin{abstract}
Increases in pro-inflammatory cytokine levels and tissue-infiltrating leukocytes have been closely linked to increased systemic and local inflammation, which result in organ injury. Previously, we demonstrated the beneficial and hepatoprotective anti-inflammatory effects of acute ethanol (EtOH) ingestion in an in vivo model of acute inflammation. Due to its undesirable side-effects, however, EtOH does not represent a therapeutic option for treatment of acute inflammation. Therefore, in this study, we compared the effects of acute EtOH exposure with ethyl pyruvate (EtP) as an alternative anti-inflammatory drug in an in vitro model of hepatic and pulmonary inflammation. Human hepatocellular carcinoma cells Huh7 and alveolar epithelial cells A549 were stimulated with either interleukin (IL) IL-1 $\beta$ ( $1 \mathrm{ng} / \mathrm{ml}, 24 \mathrm{~h}$ ) or tumor necrosis factor (TNF) $(10 \mathrm{ng} / \mathrm{ml}, 4 \mathrm{~h})$, and then treated with $\mathrm{EtP}(2.5-10 \mathrm{mM})$, sodium pyruvate $(\mathrm{NaP}, 10 \mathrm{mM})$ or $\mathrm{EtOH}$ (85-170 mM) for $1 \mathrm{~h}$. IL-6 or IL-8 release from Huh7 or A549 cells, respectively, was measured by an enzyme-linked immunosorbent assay. Neutrophil adhesion to cell monolayers and CD54 expression were also analyzed. Bcl-2 and Bax gene expression was determined by RT-qPCR, and western blot analysis was performed to determine the mechanisms involved. Treating A549 cells with either EtOH or EtP significantly reduced the IL-1 $\beta$ - or TNF-induced IL- 8 release, whereas treating Huh7 cells did not significantly alter IL-6 release. Similarly, neutrophil adhesion to stimulated A549 cells was significantly reduced by EtOH or EtP, whereas for Huh7 cells the tendency for reduced neutrophil adhesion rates by EtOH or EtP was not significant. CD54 expression was noticeably reduced in A549 cells, but this was not the case in Huh7 cells after treatment. The Bax/
\end{abstract}

Correspondence to: Dr Borna Relja, Department of Trauma, Hand and Reconstructive Surgery, University Hospital Frankfurt, Goethe University, Theodor Stern Kai 7, D-60590 Frankfurt, Germany

E-mail: info@bornarelja.com

Key words: ethanol, ethyl pyruvate, liver, lung, inflammation, in vitro
Bcl-2 ratio was dose-dependently decreased by EtOH and by high-dose EtP in A549 cells, indicating a reduction in apoptosis, whereas this effect was not observed in Huh7 cells. The underlying mechanisms involve reduced phosphorylation of Akt and nuclear factor- $\kappa \mathrm{B}(\mathrm{NF}-\kappa \mathrm{B}) \mathrm{p} 65$. We noted that as with EtP, EtOH reduced the inflammatory response in lung epithelial cells under acute inflammatory conditions. However, due to the low impact which EtP and EtOH had on the hepatocellular cells, our data suggest that both substances exerted different effects depending on the cellular entity. The possible underlying mechanisms involved the downregulation of Akt and the transcription factor $\mathrm{NF}-\kappa \mathrm{B}$, but further research on this subject is required.

\section{Introduction}

The deleterious effects of alcohol consumption have been noted in recent years. Though alcohol is a well-described immunomodulatory drug, there are inconsistencies concerning its use due to its adverse effects and associated pathologies. Excessive or chronic alcohol consumption has been associated with negative clinical outcomes and linked to one-third of all mortalities caused by traumatic injury each year $(1,2)$. Intoxicated trauma and/or burn patients are at higher risk of suffering from infectious complications, as well as pneumonia, sepsis, organ and multiple organ failure (MOF) (3-6). Regarding chronic alcohol consumption, alcohol adversely affects both recovery and outcome after trauma due to the increased risk of infectious complications compared with patients who are not not chronically intoxicated (7). Other studies have reported no increase in the risk of post-traumatic complications or worse outcome in multiple trauma patients who are primarily alcohol intoxicated $(8,9)$. Moreover, experimental and epidemiological data have confirmed that moderate alcohol consumption is associated with reduced risk of cardiovascular disease events, diabetes and coagulopathy in patients with severe, traumatic brain injury (10-12).

Alcohol is mainly metabolized in the liver, but large amounts are circulated through the lungs through bronchial circulation (13); alcohol systemically affects the liver and the respiratory system. Increased pro-inflammatory cytokine release, which has been closely linked to detrimental effects 
on health, has been reported after heavy or chronic alcohol consumption $(14,15)$. By contrast, studies on acute and/or low-dose to moderate alcohol intake have indicated potentially beneficial anti-inflammatory effects (16-20). Johansson et al and others have reported on the alcohol-reduced release of interleukin-8 (IL-8) in human endothelial and epithelial cells, their decreased interaction with neutrophils and reduced translocation of nuclear factor- $\kappa \mathrm{B}(\mathrm{NF}-\kappa \mathrm{B})$ components into the nucleus $(21,22)$. Previously, we have shown that acute alcohol consumption diminished both liver and systemic IL-6 increase, and also hepatic neutrophil infiltration in a model of acute inflammation in vivo (18).

On the one hand, alcohol may increase host susceptibility to infections due to its hypo-inflammatory effects; however, on the other hand, it hides its therapeutic potential under acute inflammatory conditions. Nevertheless, its therapeutic use is limited in clinical settings owing to its entry into the central nervous system (CNS) and the questions which remain to be answered on the dose- and time-dependent mode of action.

Ethyl pyruvate (EtP), the ester formed from ethanol (EtOH) linked to pyruvate, is a well-tolerated non-toxic compound which exerts similar anti-inflammatory effects as pyruvate $(23,24)$. Concerning the lungs, EtP has been shown to protect against ventilation-induced neutrophil infiltration and the accompanying deleterious oxidative stress (25). Hepatic injury in animals with severe acute pancreatitis, but also sepsisor hemorrhage-induced organ injuries in vivo, were prevented by EtP (26-29). Collectively, these results suggest that due to its stability, lack of adverse effects, wide therapeutic window and apparently no signs of intoxication, EtP will be useful in a clinical setting for the treatment of acute inflammation. Thus, in the present study, human alveolar epithelial and liver cells were exposed to proinflammatory stimuli and subsequently treated with alcohol or EtP in order to i) clarify the comparability of both agents concerning their anti-inflammatory potential, ii) evaluate the adequate dose, and iii) assess the cellular entity-specific efficacy of both agents.

\section{Materials and methods}

Cell culture. The human hepatocellular carcinoma cell line Huh7 and human lung adenocarcinoma cell line A549 were both purchased from Cell Line Services (Heidelberg, Germany). Cells were cultured at $37^{\circ} \mathrm{C}$ under $5 \% \mathrm{CO}_{2}$ conditions in RPMI-1640 medium (Seromed, Berlin, Germany) supplemented with $10 \%$ heat-inactivated fetal calf serum (FCS), $100 \mathrm{IU} / \mathrm{ml}$ penicillin, $100 \mu \mathrm{g} / \mathrm{ml}$ streptomycin (Gibco, Karlsruhe, Germany) and 20 mM HEPES buffer (Sigma, Steinheim, Germany) $(30,31)$. Culture media was changed every 2 or 3 days.

The isolation of polymorphonuclear neutrophils (PMNs) from healthy volunteers was in accordance with the Declaration of Helsinki and was approved by the Institutional Ethics Committee of Goethe University (Frankfurt, Germany). PMNs were isolated by density-gradient centrifugation (Polymorphprep; Nycomed, Oslo, Norway) according to the manufacturer's instructions $(30,31)$. Thereafter, PMNs were cultured in RPMI1640 medium as described above, and subsequently the number of neutrophils as well as their viability were determined by trypan blue exclusion assay. Cell cultures with a purity of $>95 \%$ were used for experiments.
Cell stimulation. The concentrations of IL-1 $\beta$ and tumor necrosis factor (TNF), as well as EtOH, EtP and sodium pyruvate $(\mathrm{NaP})$, used in this study are based on our previous work, and that of others, to allow for better comparison of data $(30,31)$. The cell lines were stimulated with either recombinant IL-1 $\beta$ ( $1 \mathrm{ng} / \mathrm{ml}$; R\&D Systems, Wiesbaden, Germany) for $24 \mathrm{~h}$ or TNF (10 ng/ml; Sigma) for $4 \mathrm{~h}$. After stimulation they were incubated with EtOH, EtP or NaP. EtOH was used at 85 and $170 \mathrm{mM}$ (corresponding to $0.5-1 \mathrm{vol} / \mathrm{vol}$ percent, corresponding to 4-7.9 $\mathrm{mg} \mathrm{EtOH} / \mathrm{ml}$ ) as described previously $(22,32,33)$. Likewise, the concentrations of EtP (2.5 and $10 \mathrm{mM})$ and $\mathrm{NaP}$ (10 mM) were chosen from previous work $(32,34)$. The cells were stimulated with either EtOH, EtP or $\mathrm{NaP}$ for $1 \mathrm{~h}$ to study the effects of acute alcohol exposure.

Cell viability. A549 and Huh7 cell viability was assessed by measuring cytoplasmic lactate dehydrogenase (LDH) activity $(30,31)$. When the plasma membrane is damaged, the cells release LDH into the cell culture supernatant. The activity of LDH in supernatants collected from cells treated with EtOH, EtP, NaP, IL-1 $\beta$ and TNF was determined enzymatically according to the manufacturer's instructions [cytotoxicity detection kit (LDH); Roche]. A549 and Huh7 viability was $>95 \%$ at the time and doses chosen for the treatment of the cells in each case. Moreover, no significant detachment of the cells was observed by microscopic evaluation of the cell layers using a Zeiss inverted fluorescence microscope (AXIO Observer Z1; Carl Zeiss AG, Oberkochen, Germany).

A trypan blue exclusion assay was used to determine the viability level of neutrophils $(30,31)$. Briefly, isolated neutrophils were stained with $0.4 \%$ trypan blue and approximately 100 cells were counted after each isolation. The mean percentage of viability was $>99 \%$.

Quantification of cytokine production. To determine the effects of EtOH, EtP and $\mathrm{NaP}$ on pro-inflammatory cytokine production, A549 or Huh7 cells were pre-incubated with either IL-1 $\beta$ (24 h) or TNF (4 h). EtOH, EtP or NaP were applied for $1 \mathrm{~h}$ after stimulation. Subsequently, IL-6 and IL- 8 were measured in culture supernatants from Huh7 and A549 cells, respectively, using the Quantikine assays (R\&D Systems) according to the manufacturer's instuctions. ELISA was performed using an Infinite M200 microplate reader (Tecan, Männedorf, Switzerland).

Ribonucleic acid (RNA) isolation, reverse transcriptionquantitative polymerase chain reaction (RT-qPCR). After stimulation with IL-1 $\beta$ or TNF and incubation with EtOH, EtP or NaP, total RNA from A549 or Huh7 cells was isolated using the RNeasy-system (Qiagen, Hilden, Germany) according to the manufacturer's instructions. Residual amounts of the remaining DNA were removed using the RNase-Free DNase kit according to the manufacturer's instructions (Qiagen). The RNA was stored at $-80^{\circ} \mathrm{C}$. The quality and amount of RNA were determined photometrically using a NanoDrop ND-1000 device (NanoDrop Technologies, Wilmington, DE, USA).

RNA was subsequently used for RT-qPCR as described previously (17). Briefly, $100 \mathrm{ng}$ total RNA was reverse transcribed using the affinity script qPCR-cDNA synthesis kit (Stratagene, La Jolla, CA, USA) following the manufacturer's 
instructions. To determine the mRNA expression of Bax and Bcl-2, RT-qPCR was carried out on a Stratagene MX3005p qPCR system (Stratagene) using gene-specific primers for human Bax and Bcl-2 (Bax: NM_004324, Hs.624291, ord. no. PPH00078B; and Bcl-2: NM_00633, Hs.150749, ord. no. PPH00079B, respectively) purchased from SABiosciences (SuperArray; Frederick, MD, USA). As a reference gene, the expression of GAPDH with human GAPDH (NM_002046, UniGene no. Hs.592355, cat. no. PPH00150E; SuperArray; SABiosciences) was determined. PCR was set up with $1 \mathrm{X} \mathrm{RT}^{2}$ SYBR-Green/Rox qPCR master mix (SABiosciences) in a $25 \mu 1$ volume according to the manufacturer's instructions. A two-step amplification protocol consisting of initial denaturation at $95^{\circ} \mathrm{C}$ for 10 min followed by 40 cycles with $15 \mathrm{sec}$ denaturation at $95^{\circ} \mathrm{C}$ and $60 \mathrm{sec}$ annealing/extension at $60^{\circ} \mathrm{C}$ was chosen. A melting-curve analysis was applied to control the specificity of amplification products. This method has been described previously (30).

Relative expression levels of the target mRNA in each sample were calculated using the comparative threshold-cycle (CT) method ( $\triangle \mathrm{CT}$ method). Briefly, the amount of target mRNA in each sample was normalized to the amount of $G A P D H$ mRNA, to provide $\triangle \mathrm{CT}$, and then to a calibrator consisting of samples obtained from unstimulated but pretreated cells. Relative Bax/Bcl-2 was then calculated.

CD54 surface expression. After stimulation with IL-1 $\beta$ or TNF and incubation with EtOH, EtP or NaP, A549 or Huh7 cells were washed in PBS [0.5\% bovine serum albumin (BSA)]. Thereafter, cells were incubated with a fluorescein-conjugated monoclonal antibody directed against CD54/intercellular adhesion molecule (ICAM)-1 (BBA20; R\&D Systems) for $60 \mathrm{~min}$ at $4^{\circ} \mathrm{C}$ as described previously $(30,31)$. CD54 expression was determined by flow cytometry using a FACSCalibur $\left(1 \times 10^{4}\right.$ cells/scan were counted; BD Biosciences, Heidelberg, Germany) and expressed as mean fluorescence units (MFU). A mouse IgG1 fluorescein antibody (IC002F; R\&D Systems) was used as the isotype control $(30,31)$.

Monolayer adhesion assay. In order to analyze PMN adhesion to pretreated A549 or Huh7 cells, A549 as well as Huh7 cells were transferred to 24-well multiplates (Falcon Primaria; Becton-Dickinson, San Jose, CA, USA) in complete RPMI-1640 medium. After reaching a confluence of $\sim 80 \%$, A549 or Huh7 cells were stimulated with either IL-1 $\beta$ or TNF, and thereafter incubated with either EtOH, EtP or NaP for 1 h. Subsequently, freshly isolated PMNs $\left(5 \times 10^{4}\right.$ cells/well) were carefully added to the A549 or Huh7 monolayers or to an empty plastic surface as controls. After $60 \mathrm{~min}$, the non-adherent PMNs were washed off 3 times using pre-warmed $\left(37^{\circ} \mathrm{C}\right)$ complete RPMI-1640 medium. The remaining PMNs were fixed with $1 \%$ glutaraldehyde. The adherent PMNs were then counted in 5 different fields of a defined size $\left(5 \times 0.25 \mathrm{~mm}^{2}\right)$ using a phase contrast microscope (x20 objective). The mean cellular adhesion rate was calculated. This assay was performed as described previously $(30,31)$.

Western blot analysis for intracellular signalling. After stimulation with IL-1 $\beta$ or TNF and subsequent incubation with $\mathrm{EtOH}$, EtP or NaP, A549 or Huh7 cells were homogenized in lysis buffer at $4^{\circ} \mathrm{C}$, followed by centrifugation for $30 \mathrm{~min}$ at $4^{\circ} \mathrm{C}$ at $20,000 \mathrm{x}$ g. Supernatants were stored at $-80^{\circ} \mathrm{C}$ for later analysis. Lysates (50 $\mu \mathrm{g}$ protein) were separated by electrophoresis on $12 \%$ polyacrylamide SDS gels and transferred to nitrocellulose membranes (Amersham-Buchler, Braunschweig, Germany). Phosphorylated Akt was detected using mouse monoclonal p-Akt antibody (cat. no. 4051S), and Akt using mouse monoclonal Akt antibody (cat. no. 4051S), respectively. Phosphorylated NF-kB was detected using mouse monoclonal p-NF-kB p65 (Ser536) antibody (cat. no. 3036S) and NF-kB using mouse monoclonal NF-kB p65 antibody (cat. no. 6956S), respectively (all antibodies were from Cell Signaling Technology, Frankfurt, Germany). Determination of $\beta$-actin with the anti- $\beta$-actin antibody (Sigma, Taufkirchen, Germany) served as a loading control. Blots were blocked (10\% non-fat dry milk in $1 \mathrm{mM}$ Tris, $150 \mathrm{mM} \mathrm{NaCl}, \mathrm{pH}$ 7.4) for $1 \mathrm{~h}$, incubated $1 \mathrm{~h}$ at room temperature with primary antibody (diluted according to the manufacturer's instructions in blocking buffer with $0.5 \%$ Tween-20 and $0.5 \%$ BSA), and subsequently incubated for $1 \mathrm{~h}$ with horseradish peroxidase-conjugated secondary antibody (sc-2005; Santa Cruz Biotechnology, Inc., Santa Cruz, CA, USA) diluted at a ratio of 1:1,000 in blocking buffer with $0.5 \%$ Tween-20 and $0.5 \%$ bovine serum albumin at room temperature. Proteins were detected with ECL ${ }^{\mathrm{TM}}$ western blot detection reagents (GE Healthcare, Munich, Germany). Blots were digitized, and the integrated density of individual bands was determined. By densitometric measurement, the amount of protein expression was normalized to $\beta$-actin, as previously described (35). The measured levels of a phosphorylated protein may change with treatment or through gel-loading errors, and thus the total level of the non-phosphorylated protein were also determined. Thus, the phosphorylated protein fraction relative to the total protein fraction serves also as an internal loading control. The activation state of Akt or p65 was calculated as the ratio of phosphorylated and total (phosphorylated plus non-phosphorylated) protein values of densitometric results in percentage form (phospho/total x 100).

Statistical analysis. Differences between groups were determined by Wilcoxon-Mann-Whitney U-test. A p-value $<0.05$ was considered to indicate a statistically significant difference. Data are represented as the means \pm standard error of the means (SEM). Statistical analyses were performed using GraphPad Prism 6 (GraphPad Software, Inc., San Diego, CA, USA). All experiments were performed 3 times.

\section{Results}

Determination of cytotoxicity. In order to evaluate the possible toxic effects of the drugs that were used, after treatment as described in Materials and methods, the LDH activity in supernatants was determined. Treating A549 and Huh7 with IL-1 $\beta$ or TNF did not have a toxic effect. Moreover, treating both cell lines with either $\mathrm{EtOH}$, EtP or $\mathrm{NaP}$ for $1 \mathrm{~h}$ did not exert any observable toxic effect either (data not shown).

Measurement of the secretory potential of A549 and Huh7 cells. In order to examine the secretory potential of the pro-inflammatory cytokines, IL- 8 release by A549 as well as the IL- 6 release by Huh7 cells was determined. Previously, the 

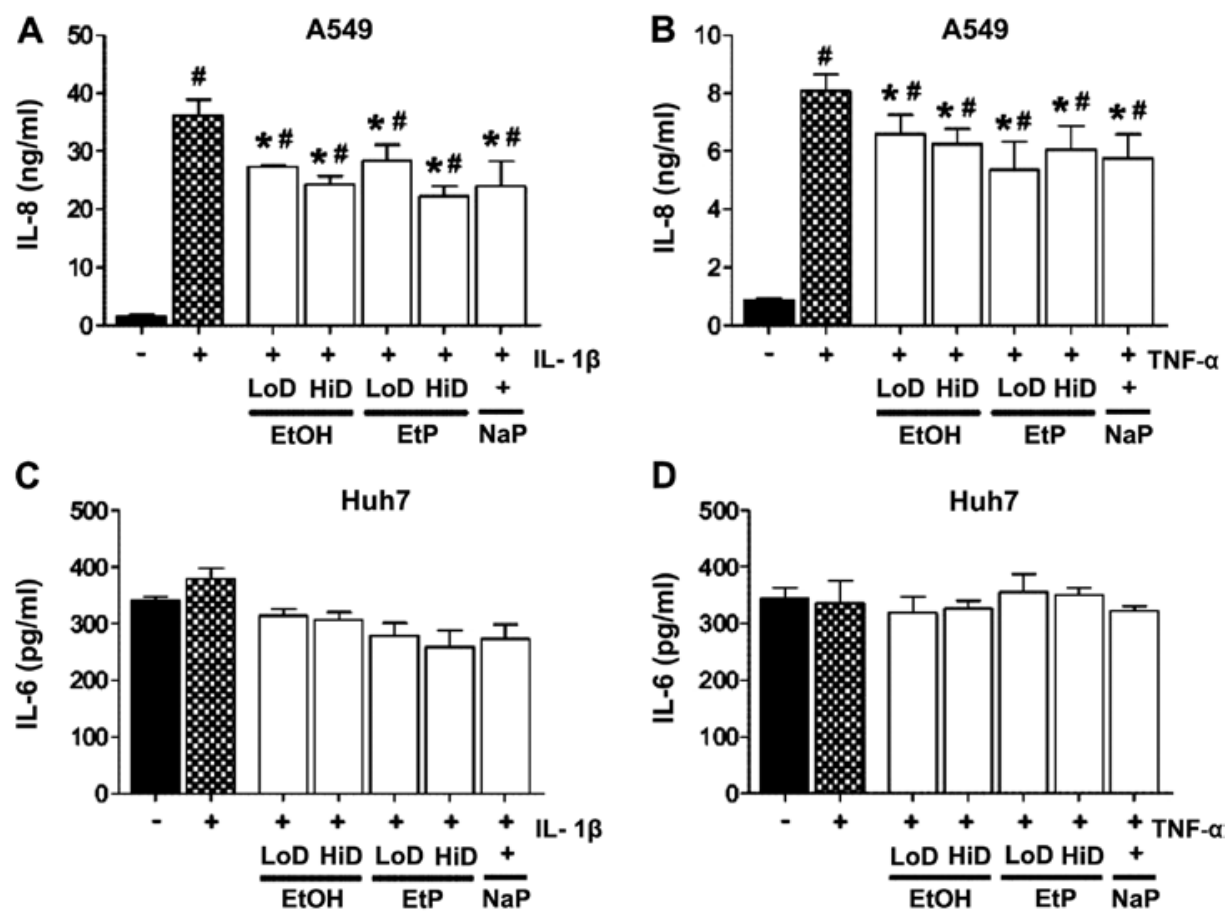

Figure 1. Effects of ethanol (EtOH), ethyl pyruvate (EtP) or sodium pyruvate (NaP) on interleukin-8 (IL-8) and IL-6 release from alveolar epithelial cells (A549) and hepatocellular carcinoma cells (Huh7) after IL-1ß (A and C) or tumor necrosis factor (TNF) (B and D) stimulation. After stimulation with either IL-1 $3(1 \mathrm{ng} / \mathrm{ml})$ for $24 \mathrm{~h}$ or TNF (10 ng/ml) for $4 \mathrm{~h}$, cells were treated with EtOH (low dose, LoD, $85 \mathrm{mM}$; high dose, HiD, $170 \mathrm{mM})$, EtP (LoD, $2.5 \mathrm{mM}$; HiD, $10 \mathrm{mM})$ or $\mathrm{NaP}(10 \mathrm{mM})$ for $1 \mathrm{~h}$. After the incubation periods, supernatants were analyzed for IL- 8 and IL- 6 concentrations. The data are presented as the means \pm SEM. $"$ p $<0.05$ vs. not pretreated and unstimulated cells; ${ }^{*} \mathrm{p}<0.05$ vs. not pretreated but stimulated control.

cells had been stimulated with IL-1 $\beta$ or TNF and were subsequently incubated with EtOH, EtP or NaP.

Lungs: IL-1 $\beta$ and TNF induced a significant release of IL-8 in A549 cells, from $1.55 \pm 0.38$ to $36.10 \pm 2.76 \mathrm{ng} / \mathrm{ml} \mathrm{IL-8} \mathrm{(}<<0.05$; Fig. 1A) and $0.89 \pm 0.03$ to $8.07 \pm 0.58 \mathrm{ng} / \mathrm{ml} \mathrm{IL-8} \mathrm{(p<0.05;}$ Fig. 1B), respectively. Treatment with EtOH for $1 \mathrm{~h}$ significantly reduced IL-8 release to $27.33 \pm 0.21 \mathrm{ng} / \mathrm{ml}$ at a low dose $(85 \mathrm{mM})$ and to $24.32 \pm 1.52 \mathrm{ng} / \mathrm{ml}$ at a high dose $(170 \mathrm{mM})$ of EtOH compared to IL-1 $\beta$-stimulated control samples $(\mathrm{p}<0.05$; Fig. 1A). Treatment with a low dose of $\mathrm{EtOH}$ for $1 \mathrm{~h}$ significantly reduced IL-8 release to $6.59 \pm 0.67 \mathrm{ng} / \mathrm{ml}$, and with high dose to $6.25 \pm 0.52 \mathrm{ng} / \mathrm{ml}$, compared to TNF-stimulated control samples $(\mathrm{p}<0.05$; Fig. 1B). IL-8 release from IL-1 $\beta$-stimulated A549 cells was significantly decreased by both doses of EtP compared to IL-1 $\beta$-stimulated control samples which were not pretreated [low dose EtP (2.5 mM): 28.34 2.78 and high dose $(10 \mathrm{mM}): 22.26 \pm 1.69 \mathrm{ng} / \mathrm{ml}, \mathrm{p}<0.05$; Fig. 1A]. Treatment with low-dose EtP significantly reduced IL-8 release to $5.36 \pm 0.95 \mathrm{ng} / \mathrm{ml}$, and with high-dose EtP to $6.06 \pm 0.80 \mathrm{ng} / \mathrm{ml}$, compared to TNF-stimulated control samples ( $\mathrm{p}<0.05$; Fig. 1B). NaP significantly reduced IL- 8 release after both IL- $1 \beta$ and TNF stimulation compared to control samples, results that were comparable to EtOH and EtP treatment (Fig. 1A and B).

Liver: In Huh7 cells, neither stimulation with IL-1 $\beta$ nor TNF induced an increase in IL-6 secretion. Similarly, the effects of EtOH, EtP and NaP treatment did not markedly affect IL-6 release from Huh7 cells (Fig. 1C and D).

\section{PMN adherence}

Lungs: The adhesion rates of PMNs to either the IL-1 $\beta$ - or TNF-stimulated A549 monolayers were significantly enhanced compared with the adhesion rates of PMNs to unstimulated A549 cells (increased to 156 and 143\%, respectively, $\mathrm{p}<0.05$; Fig. 2A and B). The treatment of stimulated A549 cells with low-dose EtOH ( $85 \mathrm{mM})$ significantly reduced PMN adhesion, and reached levels that were comparable to PMN adherence of A549 cells which were not pretreated and not stimulated ( $<<0.05$; Fig. $2 \mathrm{~A}$ and B). The treatment of IL-1 $\beta$-stimulated A549 cells with high-dose EtOH $(170 \mathrm{mM})$ did not markedly reduce $\mathrm{PMN}$ adhesion, whereas this reduction was significant in the TNF-stimulated A549 cells ( $p<0.05$; Fig. 2A and B). The treatment of both IL-1 $\beta$ - and TNF-stimulated A549 cells with both high and low doses of EtP significantly diminished PMN adhesion in most cases $(\mathrm{p}<0.05)$. Treatment with NaP exerted comparable effects to treatment with high-dose EtP (Fig. 2A and $\mathrm{B})$.

Liver: Experiments concerning the stimulation and subsequent treatment of Huh7 cells did not deliver statistically significant data (Fig. 2C and D).

\section{CD54 protein expression}

Lungs: IL-1 $\beta$ or TNF stimulation of A549 cells induced a significant increase in cell-surface CD54 protein expression compared to unstimulated A549 cells (IL-1 $\beta$ : $22.84 \pm 2.99$ vs. $2.61 \pm 0.53$ MFU; and TNF: $20.30 \pm 3.05$ vs. $2.61 \pm 0.53 \mathrm{MFU}, \mathrm{p}<0.05$; Fig. 3A and B). Treating stimulated A549 cells with EtOH, EtP or NaP reduced the increased adhesion rates (Fig. $3 \mathrm{~A}$ and $\mathrm{B}$ ), although this reduction was not as significant in comparison to the previously described reduction in PMN adhesion in stimulated A549 cells.

Liver: We noted that the stimulation of Huh7 cells with IL-1 $\beta$ induced a significant increase in CD54 expression 

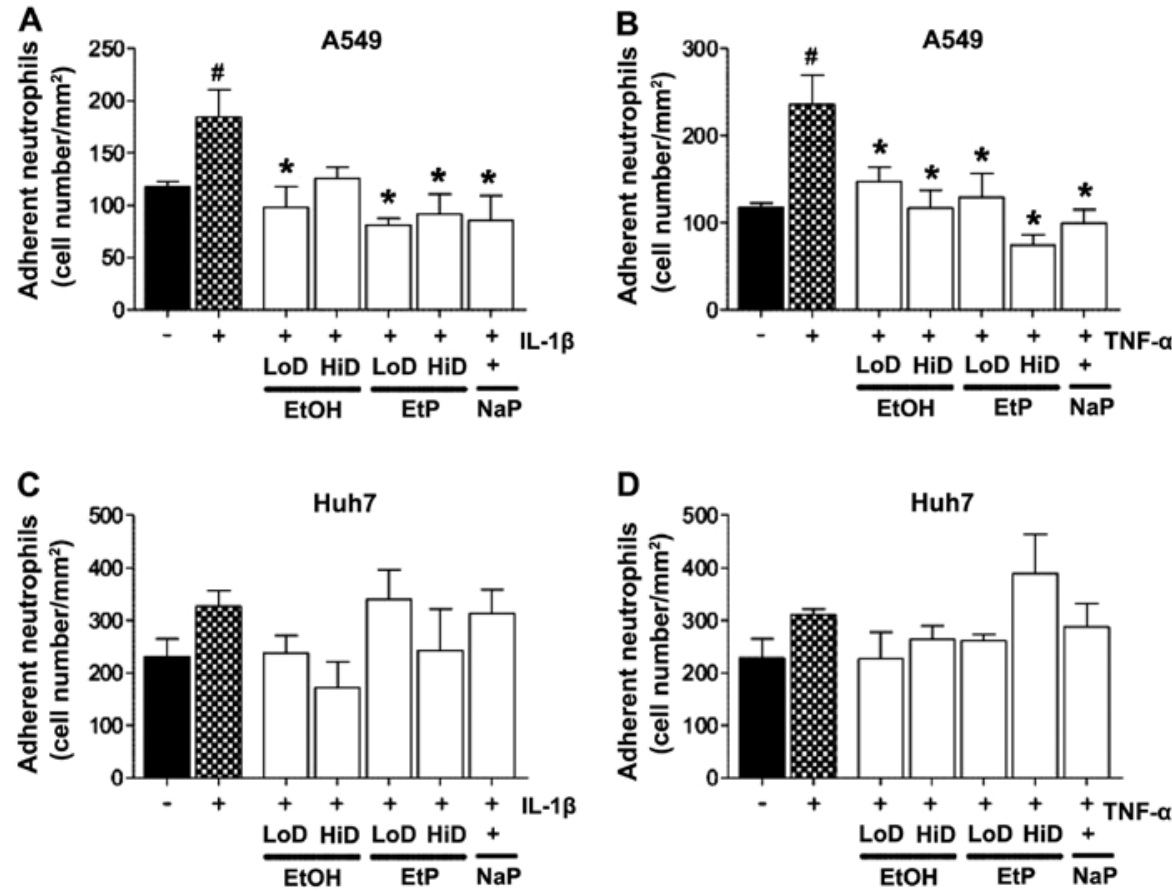

Figure 2. Effects of ethanol (EtOH), ethyl pyruvate (EtP) or sodium pyruvate (NaP) on the adhesiveness of neutrophils to alveolar epithelial cells (A549) and

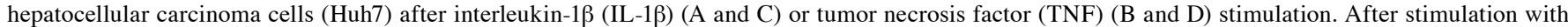
either IL-1 $(1 \mathrm{ng} / \mathrm{ml})$ for $24 \mathrm{~h}$ or TNF $(10 \mathrm{ng} / \mathrm{ml})$ for $4 \mathrm{~h}$, cells were treated with EtOH (low dose, LoD, $85 \mathrm{mM}$; high dose, HiD, $170 \mathrm{mM})$, EtP (LoD, $2.5 \mathrm{mM}$; $\mathrm{HiD}, 10 \mathrm{mM})$ or $\mathrm{NaP}(10 \mathrm{mM})$ for $1 \mathrm{~h}$. After the incubation periods, neutrophils were added and the adhesion capacity was analyzed. The data are presented as the means \pm SEM. ${ }^{\#} p<0.05$ vs. not pretreated and unstimulated cells; ${ }^{*} p<0.05$ vs. not pretreated but stimulated control.

A

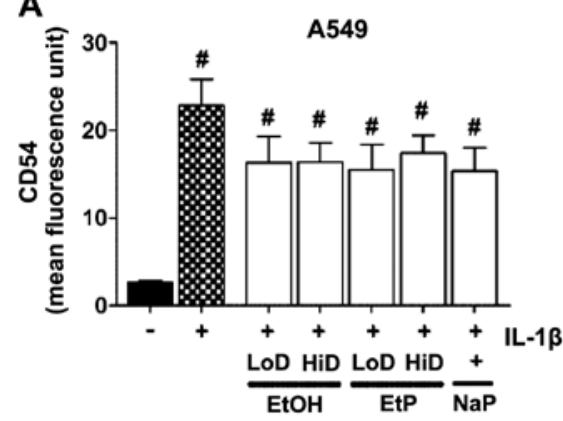

C

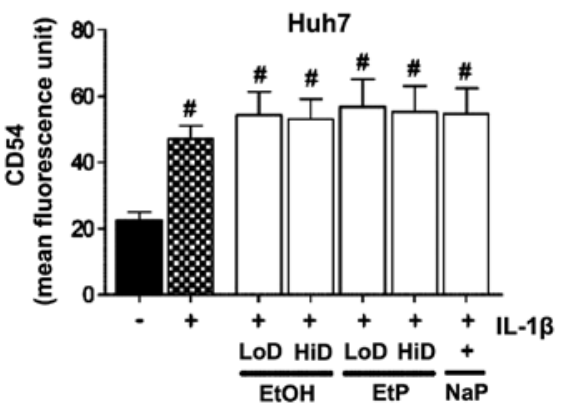

B

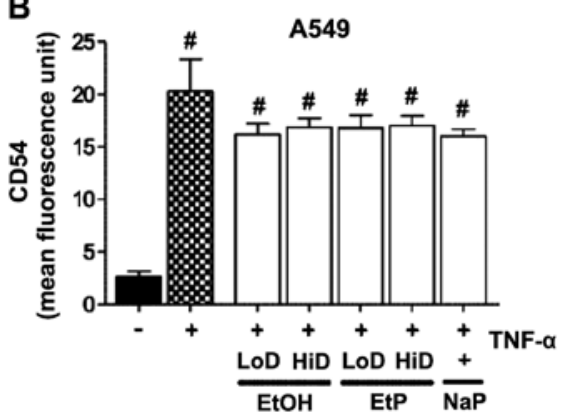

D

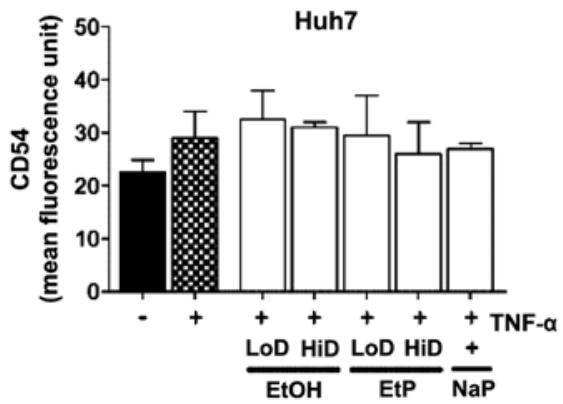

Figure 3. Effects of ethanol (EtOH), ethyl pyruvate (EtP) or sodium pyruvate (NaP) on the surface expression of CD54 in alveolar epithelial cells (A549) and

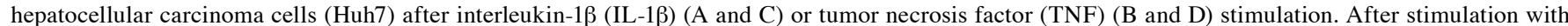
either IL-1 $(1 \mathrm{ng} / \mathrm{ml})$ for $24 \mathrm{~h}$ or TNF $(10 \mathrm{ng} / \mathrm{ml})$ for $4 \mathrm{~h}$, cells were treated with EtOH (low dose, LoD, $85 \mathrm{mM}$; high dose, HiD, $170 \mathrm{mM})$, EtP (LoD, $2.5 \mathrm{mM}$; $\mathrm{HiD}, 10 \mathrm{mM})$ or $\mathrm{NaP}(10 \mathrm{mM})$ for $1 \mathrm{~h}$. After the incubation periods, CD54 expression was evaluated (represented as mean fluorescence units, MFUs). The data are presented as the means \pm SEM. ${ }^{*} \mathrm{p}<0.05$ vs. not pretreated and unstimulated cells.

compared to unstimulated cells $(47.00 \pm 4.00$ vs. $22.50 \pm 2.39$ MFU, p<0.05) (Fig. 3C). However, as shown in Fig. 3D, TNF stimulation did not markedly affect CD54 expression.
Treatment of the stimulated Huh7 cells with EtOH, EtP or NaP did not induce considerable changes in the CD54 expression levels (Fig. 3C and D). 
A
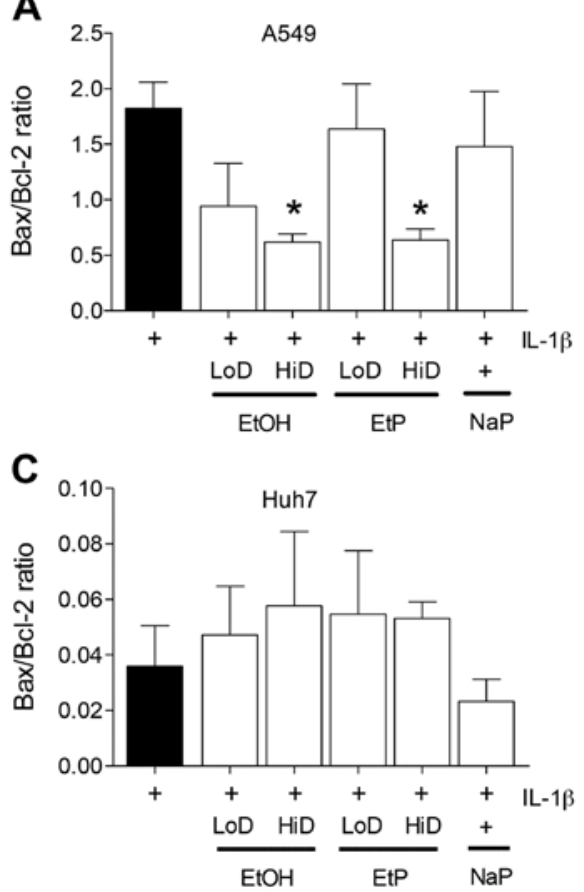

B
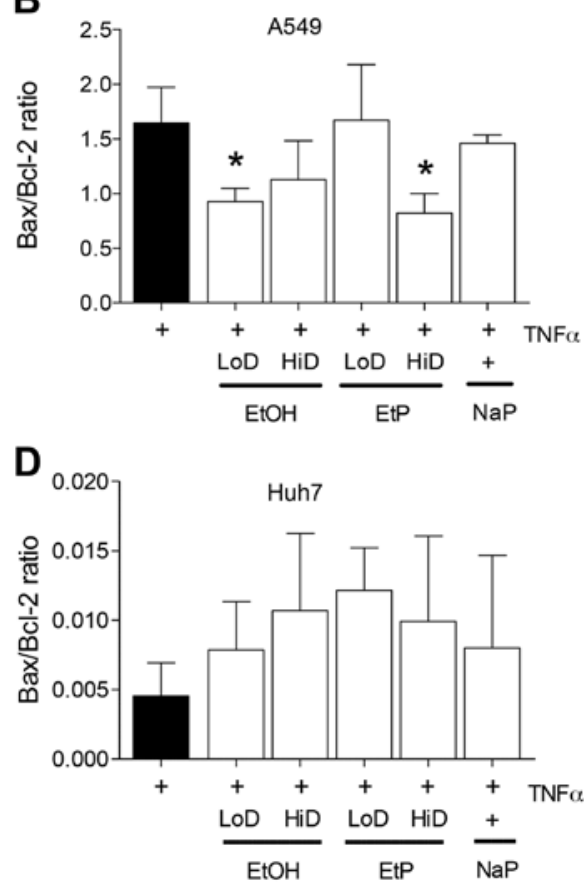

Figure 4. Effects of ethanol (EtOH), ethyl pyruvate (EtP) or sodium pyruvate (NaP) on apoptosis of alveolar epithelial cells (A549) or hepatocellular carcinoma cells (Huh7) after interleukin-1 $\beta$ (IL-1 $\beta$ ) (A and C) or tumor necrosis factor (TNF) (B and D) stimulation. After stimulation with either IL-1 $\beta$ (1 ng/ml) for $24 \mathrm{~h}$ or TNF $(10 \mathrm{ng} / \mathrm{ml})$ for $4 \mathrm{~h}$, cells were treated with EtOH (low dose, LoD, $85 \mathrm{mM}$; high dose, HiD, $170 \mathrm{mM})$, EtP (LoD, $2.5 \mathrm{mM}$; HiD, $10 \mathrm{mM})$ or NaP $(10 \mathrm{mM})$ for $1 \mathrm{~h}$. After the incubation periods, Bax/Bcl-2 gene expression ratio was analyzed. The data are presented as the means $\pm \mathrm{SEM}$. ${ }^{*} \mathrm{p}<0.05 \mathrm{vs}$. not pretreated but stimulated control.

Gene expression of apoptosis-related Bax/Bcl-2

Lungs: RT-qPCR demonstrated that an increase in the Bax/Bcl-2 ratio occurred in A549 cells after they were stimulated with either IL-1 $\beta$ or TNF relative to the unstimulated control cells (1.81 or 1.67 ) (Fig. $4 \mathrm{~A}$ and $\mathrm{B}$ ). The $\mathrm{Bax} / \mathrm{Bcl}-2$ ratio was significantly decreased by $38.3 \%$ in IL- $1 \beta$-stimulated A549 cells after treatment with high-dose EtOH compared to A549 cells which were stimulated but not pretreated $(\mathrm{p}<0.05)$ (Fig. 4A). Low-dose $\mathrm{EtOH}$ reduced the $\mathrm{Bax} / \mathrm{Bcl}-2$ ratio, but this reduction was not designated significant. Treatment with high-dose EtP caused a significant reduction in the $\mathrm{Bax} / \mathrm{Bcl}-2$ ratio after stimulation of cells with IL-1 $\beta$ (reduced by $40.1 \%$ ) compared to stimulated A549 control ( $\mathrm{p}<0.05$ ) (Fig. 4A). The IL-1 $\beta$-induced increase in $\mathrm{Bax} / \mathrm{Bcl}-2$ ratio was not significantly altered by $\mathrm{NaP}$.

After stimulation of A549 cells with TNF, we noted that the $\mathrm{Bax} / \mathrm{Bcl}-2$ ratio was significantly decreased by low-dose $\mathrm{EtOH}$ as well a high dose of EtP $(\mathrm{p}<0.05)$ (Fig. 4B), whereas $\mathrm{NaP}$ did not induce significant changes in Bax/Bcl-2 expression (Fig. 4B).

Liver: The Bax/Bcl-2 ratio was not significantly altered in Huh7 after stimulation of cells with IL-1 $\beta$ or TNF (Fig. 4C and D).

Protein expression of $A k t$ and $N F-\kappa B$. To analyze the signaling cascades involved in the effects described above, the role of Akt and $\mathrm{NF}-\kappa \mathrm{B}$ in stimulated and treated A549 cells was evaluated by detection of phosphorylated and unphosphorylated Akt and $\mathrm{NF}-\kappa \mathrm{B}$ by western blot analysis in cell homogenates (Fig. 5). The protein levels of Akt were similar in all groups. The relative protein levels of phosphorylated Akt were barely detectable in unstimulated controls, whereas the expression of phosphory- lated Akt was increased by IL-1 $\beta$ stimulation (Fig. 5A). The relative protein levels of phosphorylated Akt were reduced by treatment with EtOH, EtP and $\mathrm{NaP}$ (Fig. 5A). The expression levels of unphosphorylated and phosphorylated NF- $\mathrm{B}$ were similar to those results obtained from analyses of Akt. The quantification of $\mathrm{Akt}$ and $\mathrm{NF}-\kappa \mathrm{B}$ expression revealed that both Akt and NF-kB phosphorylation, after stimulation of A549 cells with IL-1 $\beta$, was significantly enhanced compared to unstimulated A549 cells (Fig. 5B and C). This increase in both Akt and NF- $\mathrm{NB}$ phosphorylation after IL-1 $\beta$ stimulation was decreased by EtOH, EtP and $\mathrm{NaP}$ treatment, and reached levels of phosphorylation that were comparable to the expression levels of unstimulated cells (Fig. 5B and C).

\section{Discussion}

In the present study, we evaluated the effects of acute alcohol or EtP on the pro-inflammatory responses induced by IL-1 $\beta$ or TNF stimulation of human lung epithelial or liver cells, respectively. Exposure of lung epithelial cells to either EtOH or EtP significantly reduced IL-1 $\beta$ - or TNF-induced IL- 8 release. Similarly, the adhesion capacity of isolated neutrophils to stimulated lung cells was significantly reduced by EtOH or EtP, and this result was paralleled by notably reduced CD54 expression. The Bax/Bcl-2 ratio indicated that both EtOH and the high dose of EtP reduced the apoptosis of lung cells. The underlying anti-inflammatory mechanisms appear to involve the reduced phosphorylation of Akt and NF- $\mathrm{BB}$ p65. The exposure of liver cells to either EtOH or EtP did not induce similar effects to those observed in lung cells. In summary, EtP reduced to EtOH levels the inflammatory response in lung epithelial cells under 

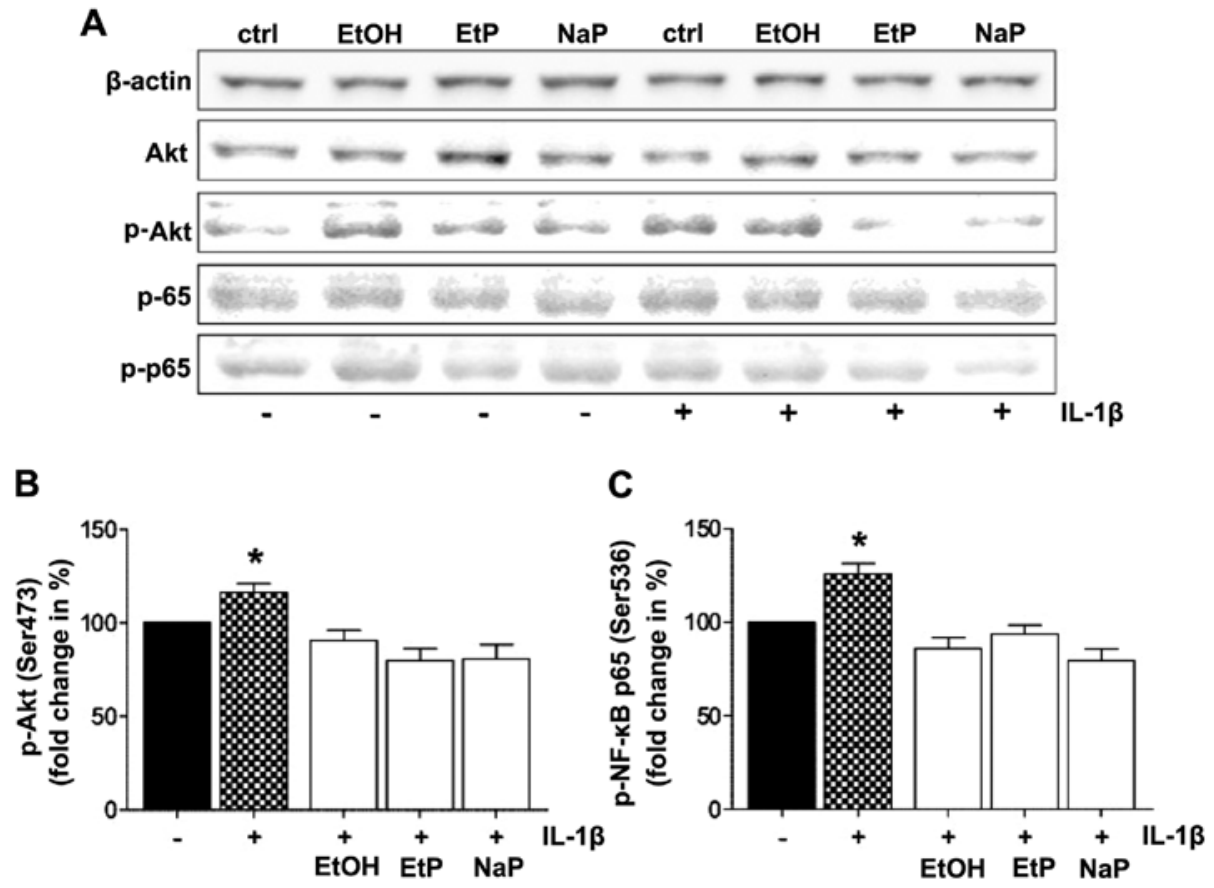

Figure 5. Effects of ethanol (EtOH), ethyl pyruvate (EtP) or sodium pyruvate (NaP) on Akt and nuclear factor- $\mathrm{B}$ (NF- $\mathrm{kB}$ ) (phosphorylated and unphosphory-

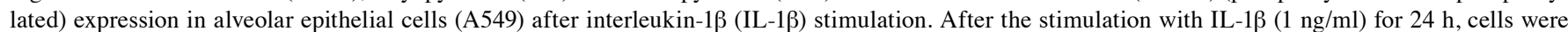
treated with EtOH, EtP or NaP for $1 \mathrm{~h}$. After the incubation periods, proteins were harvested and analyzed by western blot analysis (A). After normalization to $\beta$-actin expression, the activation state of Akt or p65 was calculated as the ratio of phosphorylated and total (phosphorylated plus non-phosphorylated) protein values of densitometry results (B and C). The ratio of cells which were not pretreated and not stimulated was set as $100 \%$. The data are presented as the means \pm SEM. ${ }^{*} p<0.05$ vs. not pretreated and not stimulated control (ctrl).

acute inflammatory conditions. However, due to the low impact on the hepatocellular cells which we noted, the data suggest that EtP and EtOH have different effects depending on the cellular entity and also on the use of the pro-inflammatory stimulus.

Although alcohol is a well-described immunomodulatory drug, serious inconsistencies regarding its use and subsequent effects on associated pathologies have been previously noted. Despite numerous reports on the deleterious effects of chronic or excessive alcohol abuse, others and our group have reported that moderate or acute use may exert beneficial effects $(15-17,20,36)$. The negative effects of alcohol consumption have been linked to an increased inflammatory response, including increased cytokine release $(14,15,37,38)$. Pro-inflammatory cytokines such as IL-1 $\beta$, TNF, IL-6 and IL- 8 have been identified as important contributors to the pathogenesis of organ damage, including lung as well as liver injury in models of acute inflammation (17-19,39-42). Together with IL-6, IL-8 binds to molecules that are involved in neutrophil activation, trafficking and infiltration of tissues in models of acute lung and liver injury $(18,43)$. Interestingly, both IL-6 and IL- 8 are modulated by alcohol: while chronic alcohol consumption has been proven to increase their expression and release, acute alcohol consumption reduced the lipopolysaccharide (LPS)-induced IL-6 release from macrophages (44). Short-term alcohol exposure reduced IL-8 release from human umbilical vein cells (HUVECs) or lung epithelial cells, but considerable inhibitory effects on the cellular interactions with neutrophils were also noted, suggesting that reduced nuclear translocation of NF- $\mathrm{KB}$ components was also involved $(21,22)$. In the present study, IL-8 release from lung epithelial cells after stimulation with either IL-1 $\beta$ or TNF was markedly reduced by EtOH and EtP treatment (Fig. 1). These data suggest that EtOH and EtP both exerted potent anti-inflammatory effects on lung epithelial cells in our in vitro model of acute inflammation. In line with these findings, Bhatty et al (2001) demonstrated that treating mice with $\sim 87 \mathrm{mM}$ alcohol and then challenging them intraperitoneally with non-pathogenic E. coli suppressed the production of the majority of known proinflammatory cytokines (45).

Neutrophils, as essential components of the host defense and the innate immune system, are responsible for combating infections; it has been demonstrated that reducing neutrophil presence at sites of inflammation improved organ integrity, as activated neutrophils have the potential to harm the injured tissue (46). Moreover, reduced tissue infiltration by neutrophils was closely associated with decreased CD54 expression (47). Jonsson and Palmblad have demonstrated that increased CD54 expression in HUVECs after stimulation with LPS resulted in enhanced adhesion rates of neutrophils to endothelial monolayers (22). In line with these findings, we have shown in the present study that stimulating lung epithelial cells with pro-inflammatory cytokines markedly increased neutrophil adhesion to these cells as well as the expression of CD54 (Figs. 2 and 3). Treating these cells with EtOH decreased cytokine-induced adhesion capacity, and CD54 expression rates were also lowered but the decrease was not so considerable. It has previously been noted that treating lung epithelial cells with alcohol after they were stimulated with IL-6 decreased neutrophil adhesion to these cells, but CD54 expression was not markedly altered $(30,31)$. These findings suggest that other mechanisms aside from CD54 downregulation are involved in reducing neutrophil adhesion, possibly $\mathrm{CD} 31$ or $\mathrm{CD} 62 \mathrm{~L}$. 
As well as functional effects, it has been noted that treating stimulated lung epithelial cells with alcohol reduced apoptotic changes induced by the stimulation with pro-inflammatory cytokines. Acute alcohol exposure markedly diminished tissue damage in an in vivo model of acute inflammation (18). Interestingly, here, there are anti-apoptotic effects of alcohol on lung epithelial cells. Our analysis of underlying pathways demonstrated predominantly reduced activation of Akt and NF- $\mathrm{KB}$ after acute alcohol exposure of stimulated lung epithelial cells (Fig. 5). The mechanism via NF- $\mathrm{kB}$ for the anti-inflammatory effects of alcohol on lung epithelial cells has been suggested previously $(22,32)$. However, to the best of our knowledge, the involvement of Akt had not been described previously.

While beneficial results were observed for lung cells, no similar data were observed for liver cells, suggesting a cell-type specific mode of action for the substances that were applied (Fig. 1). In our previous in vivo studies, we have shown that acute alcohol consumption exerted liver-protective effects, through diminished systemic and local anti-inflammatory effects in our model of acute inflammation $(18,19)$. Previously, we have also demonstrated that acute alcohol ingestion diminished the neutrophil infiltration of the liver in the same in vivo model (18). In this study, we noted that stimulating liver cells with IL-1 $\beta$ significantly enhanced CD54 expression compared with control. We noted increased adhesion rates of PMNs to stimulated liver cells, but the data confirmed that although there was a tendency to increased PMN adhesion to Huh7, this effect was not significant. One rationale is that, compared with lung cells, Huh7 had stronger baseline CD54 expression as well as higher baseline adhesion rates of PMNs to untreated controls. Possibly, due to this, the findings regarding Huh7 cells were not as prominent as they were in A549 cells. This is one explanation as to why the observed data in Huh7 was not as clear as data from A549 cells. With regard to the anti-apoptotic effects of alcohol, liver cells were not as sensitive to alcohol either (Fig. 4). It is possible that stimulating Huh7 cells with IL-1 $\beta$ or TNF does not induce apoptosis, as was observed in lung epithelial cells. Additional cell lines should be used in future studies in order to monitor liver tissue.

However, given the adverse effects of alcohol regarding its entry into the CNS but also the risk of addiction, its practical use in clinical settings as a therapy option is rather limited. Comparing the therapeutic potential of EtP with $\mathrm{EtOH}, \mathrm{EtP}$ is a safe and well-tolerated drug (23). Moreover, the anti-inflammatory potential of EtOH was mimicked by EtP in lung epithelial cells. Johansson and Palmblad have demonstrated this anti-inflammatory potential previously (48). However, no underlying mechanism was described previous to the present study, to the best of our knowledge. In the present study, we noted that EtP, like EtOH, reduced both Akt and NF- $\mathrm{kB}$ phosphorylation, which possibly resulted in diminished pro-inflammatory cytokine release, reduced neutrophil adhesion rates to stimulated lung epithelial cells or lowered CD54 expression. Therefore, EtP likely represents a useful therapeutic tool that should be investigated in further studies. Regarding $\mathrm{NaP}$, its effects often mimicked those of EtP. However, NaP appears to be anti-proliferative rather than anti-apoptotic. These findings suggest that the pyruvate moiety of both molecules has potent anti-inflammatory potential, whereas the ethyl moiety of EtP or EtOH is responsible for the anti-apoptotic effects. However, this hypothesis should be evaluated in further studies.

Notably, the previously described effects were observed only in lung epithelial cells in our study, whereas liver cells appeared relatively unaffected by various treatment options, and the stimuli used. It is possible that the hepatocellular cell line Huh7, which was used in the present study, was not sensitive to the stimuli that were chosen. Furthermore, treatment with either EtOH, EtP or NaP may simply be cell-type specific. This remains a limitation of our study and will be the subject of further studies. In future studies, to exclude the possible effects of an unknown lack of sensitivity of Huh7 cells to certain substances, and in order to further strengthen the data from this study, the experiments should be performed on more than one 'tissue-specific' cell line. While the same treatment may be beneficial for one tissue entity, it may be disadvantageous when using another treatment strategy (e.g., timing) or other tissues. Therefore, applying different treatment strategies to other cell lines deriving from various tissues will markedly improve the findings. Furthermore, the effects of prolonged incubation periods with both EtOH and pyruvate were not evaluated in this study and remain to be seen. Modulations of CD54 expression were rather inconsistent regarding the expected and observed adhesion rates from neutrophils to lung or liver cells. Other adhesion-related proteins and cell lines should thus be evaluated in future studies. Another limiting factor of this study is that the protein activation state was evaluated by western blot analysis and not by a protein kinase activity assay. This remains to be elucidated in future studies.

In conclusion, the pro-inflammatory cytokine release from lung epithelial cells induced by inflammatory cytokines was reduced by both EtOH and EtP treatment. Moreover, both EtOH and EtP reduced the expression of the intercellular adhesion molecules, resulting in associated decreased neutrophil adhesion rates to lung epithelial monolayers. Additionally, both substances exerted anti-apoptotic potential. We suggest that the underlying mechanisms for these effects involve the downregulated activation of Akt and NF- $\mathrm{kB}$. Due to similarly strong effects as well as pathways involved, and also its stability, EtP is likely a potential therapeutic tool which can be used in a pre-clinical setting for the treatment of acute inflammation.

\section{Acknowledgements}

We would like to thank Kerstin Kontradowitz, Alexander Schaible and Katrin Jurida for outstanding technical assistance. This study was supported by DFG PE908/3-1 and RE3304/5-1.

\section{References}

1. Li G, Keyl PM, Smith GS and Baker SP: Alcohol and injury severity: reappraisal of the continuing controversy. J Trauma 42 : $562-569,1997$.

2. Rehm J, Room R, Graham K, Monteiro M, Gmel G and Sempos CT: The relationship of average volume of alcohol consumption and patterns of drinking to burden of disease: an overview. Addiction 98: 1209-1228, 2003.

3. Brattström O, Granath F, Rossi P and Oldner A: Early predictors of morbidity and mortality in trauma patients treated in the intensive care unit. Acta Anaesthesiol Scand 54: 1007-1017, 2010.

4. Griffin R, Poe AM, Cross JM, Rue LW III and McGwin G Jr: The association between blood alcohol level and infectious complications among burn patients. J Burn Care Res 30: 395-399, 2009. 
5. Messingham KA, Faunce DE and Kovacs EJ: Alcohol, injury, and cellular immunity. Alcohol 28: 137-149, 2002.

6. Moore EC, Padiglione AA, Wasiak J, Paul E and Cleland H: Candida in burns: risk factors and outcomes. J Burn Care Res 31: 257-263, 2010.

7. Jurkovich GJ, Rivara FP, Gurney JG, Fligner C, Ries R, Mueller BA and Copass M: The effect of acute alcohol intoxication and chronic alcohol abuse on outcome from trauma. JAMA 270: 51-56, 1993.

8. Nau C, Wutzler S, Dorr H, Lehnert M, Lefering R, Laurer H, Wyen $\mathrm{H}$ and Marzi I: Liver cirrhosis but not alcohol abuse is associated with impaired outcome in trauma patients - a retrospective, multicentre study. Injury 44: 661-666, 2013.

9. Zeckey C, Dannecker S, Hildebrand F, Mommsen P, Scherer R, Probst C, Krettek C and Frink M: Alcohol and multiple trauma: is there an influence on the outcome? Alcohol 45: 245-251, 2011.

10. Berger K, Ajani UA, Kase CS, Gaziano JM, Buring JE, Glynn RJ and Hennekens CH: Light-to-moderate alcohol consumption and risk of stroke among U.S. male physicians. N Engl J Med 341: $1557-1564,1999$.

11. Lustenberger T, Inaba K, Barmparas G, Talving P, Plurad D, Lam L, Konstantinidis A and Demetriades D: Ethanol intoxication is associated with a lower incidence of admission coagulopathy in severe traumatic brain injury patients. J Neurotrauma 28: 1699-1706, 2011.

12. Sesso HD: Alcohol and cardiovascular health: recent findings. Am J Cardiovasc Drugs 1: 167-172, 2001

13. Kaphalia L and Calhoun WJ: Alcoholic lung injury: metabolic, biochemical and immunological aspects. Toxicol Lett 222: 171-179, 2013.

14. Burnham EL, Kovacs EJ and Davis CS: Pulmonary cytokine composition differs in the setting of alcohol use disorders and cigarette smoking. Am J Physiol Lung Cell Mol Physiol 304: L873-L882, 2013.

15. Cook RT: Alcohol abuse, alcoholism, and damage to the immune system - a review. Alcohol Clin Exp Res 22: 1927-1942, 1998.

16. Mandrekar P, Catalano D, White B and Szabo G: Moderate alcohol intake in humans attenuates monocyte inflammatory responses: inhibition of nuclear regulatory factor kappa $B$ and induction of interleukin 10. Alcohol Clin Exp Res 30: 135-139, 2006.

17. Relja B, Henrich D, Wetzel G, Sander AL, Jakob H, Maraslioglu M, Marzi I and Lehnert M: Effects of acute ethanol gavage on intestinal integrity after hemorrhage/resuscitation. Scand J Gastroenterol 48: 448-458, 2013

18. Relja B, Höhn C, Bormann F, Seyboth K, Henrich D, Marzi I and Lehnert M: Acute alcohol intoxication reduces mortality, inflammatory responses and hepatic injury after haemorrhage and resuscitation in vivo. Br J Pharmacol 165: 1188-1199, 2012.

19. Relja B, Wilhelm K, Wang M, Henrich D, Marzi I and Lehnert M: Acute ethanol gavage attenuates hemorrhage/resuscitation-induced hepatic oxidative stress in rats. Oxid Med Cell Longev 2012: 983427, 2012.

20. Szabo G, Mandrekar P, Girouard L and Catalano D: Regulation of human monocyte functions by acute ethanol treatment: decreased tumor necrosis factor-alpha, interleukin-1 beta and elevated interleukin-10, and transforming growth factor-beta production. Alcohol Clin Exp Res 20: 900-907, 1996.

21. Johansson AS, Lidén J, Okret S and Palmblad JE: Effects of ethanol on cytokine generation and NFkappaB activity in human lung epithelial cell. Biochem Pharmacol 70: 545-551, 2005.

22. Jonsson AS and Palmblad JE: Effects of ethanol on NF-kappaB activation, production of myeloid growth factors, and adhesive events in human endothelial cells. J Infect Dis 184: 761-769, 2001.

23. Fink MP: Ethyl pyruvate. Curr Opin Anaesthesiol 21: 160-167, 2008 .

24. Kao KK and Fink MP: The biochemical basis for the antiinflammatory and cytoprotective actions of ethyl pyruvate and related compounds. Biochem Pharmacol 80: 151-159, 2010.

25. Li LF, Kao KC, Yang CT, Huang CC and Liu YY: Ethyl pyruvate reduces ventilation-induced neutrophil infiltration and oxidative stress. Exp Biol Med (Maywood) 237: 720-727, 2012.

26. Cai B, Brunner M, Wang H, Wang P, Deitch EA and Ulloa L: Ethyl pyruvate improves survival in awake hemorrhage. J Mol Med Berl 87: 423-433, 2009.

27. Cai B, Deitch EA, Grande D and Ulloa L: Anti-inflammatory resuscitation improves survival in hemorrhage with trauma. J Trauma 66: 1632-1639, discussion 1639-1640, 2009.

28. Luan ZG, Zhang H, Ma XC, Zhang C and Guo RX: Therapeutic treatment with ethyl pyruvate attenuates the severity of liver injury in rats with severe acute pancreatitis. Pancreas 41: 729-737, 2012.
29. Ulloa L, Ochani M, Yang H, Tanovic M, Halperin D, Yang R, Czura CJ, Fink MP and Tracey KJ: Ethyl pyruvate prevents lethality in mice with established lethal sepsis and systemic inflammation. Proc Natl Acad Sci USA 99: 12351-12356, 2002.

30. Relja B, Omid N, Kontradowitz K, Jurida K, Oppermann E, Störmann P, Werner I, Juengel E, Seebach C and Marzi I: Decreased inflammatory responses of human lung epithelial cells after ethanol exposure are mimicked by ethyl pyruvate. Mediators Inflamm 2014: 781519, 2014.

31. Relja B, Omid N, Schaible A, Perl M, Meier S, Oppermann E, Lehnert M and Marzi I: Pre- or post-treatment with ethanol and ethyl pyruvate results in distinct anti-inflammatory responses of human lung epithelial cells triggered by interleukin-6. Mol Med Rep 12: 2991-2998, 2015

32. Johansson AS, Johansson-Haque K, Okret S and Palmblad J: Ethyl pyruvate modulates acute inflammatory reactions in human endothelial cells in relation to the NF-kappaB pathway. Br J Pharmacol 154: 1318-1326, 2008

33. Maiya R, Buck KJ, Harris RA and Mayfield RD: Ethanol-sensitive sites on the human dopamine transporter. J Biol Chem 277: 30724-30729, 2002.

34. Famili A, Ammar DA and Kahook MY: Ethyl pyruvate treatment mitigates oxidative stress damage in cultured trabecular meshwork cells. Mol Vis 19: 1304-1309, 2013.

35. Relja B, Meder F, Wilhelm K, Henrich D, Marzi I and Lehnert M: Simvastatin inhibits cell growth and induces apoptosis and G0/G1 cell cycle arrest in hepatic cancer cells. Int J Mol Med 26: 735-741, 2010.

36. Ajisaka $\mathrm{H}$, Okajima M, Goto $\mathrm{Y}$, Taniguchi $\mathrm{T}$ and Inaba $\mathrm{H}$ : Effects of acute low-dose ethanol on inflammatory reactions to endotoxin-induced shock in rats. J Toxicol Sci 37: 649-654, 2012.

37. Maraslioglu M, Oppermann E, Blattner C, Weber R, Henrich D, Jobin C, Schleucher E, Marzi I and Lehnert M: Chronic ethanol feeding modulates inflammatory mediators, activation of nuclear factor- $\mathrm{KB}$, and responsiveness to endotoxin in murine Kupffer cells and circulating leukocytes. Mediators Inflamm 2014: 808695, 2014

38. Maraslioglu M, Weber R, Korff S, Blattner C, Nauck C, Henrich D, Jobin C, Marzi I and Lehnert M: Activation of NF- $\kappa$ B after chronic ethanol intake and haemorrhagic shock/resuscitation in mice. Br J Pharmacol 170: 506-518, 2013.

39. Do-Umehara HC, Chen C, Urich D, Zhou L, Qiu J, Jang S, Zander A, Baker MA, Eilers M, Sporn PH, et al: Suppression of inflammation and acute lung injury by Mizl via repression of C/EBP- $\delta$. Nat Immunol 14: 461-469, 2013.

40. Allen TC and Kurdowska A: Interleukin 8 and acute lung injury. Arch Pathol Lab Med 138: 266-269, 2014

41. Monção-Ribeiro LC, Cagido VR, Lima-Murad G, Santana PT, Riva DR, Borojevic R, Zin WA, Cavalcante MC, Riça I, Brando-Lima AC, et al: Lipopolysaccharide-induced lung injury: Role of P2X7 receptor. Respir Physiol Neurobiol 179: 314-325, 2011.

42. Zhu T, Wang DX, Zhang W, Liao XQ, Guan X, Bo H, Sun JY, Huang NW, He J, Zhang YK, et al: Andrographolide protects against LPS-induced acute lung injury by inactivation of NF- $\kappa B$. PLoS One 8: e56407, 2013.

43. Reiss LK, Uhlig U and Uhlig S: Models and mechanisms of acute lung injury caused by direct insults. Eur J Cell Biol 91: 590-601, 2012

44. Karavitis J, Murdoch EL, Gomez CR, Ramirez L and Kovacs EJ Acute ethanol exposure attenuates pattern recognition receptor activated macrophage functions. J Interferon Cytokine Res 28: 413-422, 2008

45. Bhatty M, Jan BL, Tan W, Pruett SB and Nanduri B: Role of acute ethanol exposure and TLR4 in early events of sepsis in a mouse model. Alcohol 45: 795-803, 2011.

46. Segel GB, Halterman MW and Lichtman MA: The paradox of the neutrophil's role in tissue injury. J Leukoc Biol 89: 359-372, 2011.

47. Relja B, Töttel E, Breig L, Henrich D, Schneider H, Marzi I and Lehnert M: Effects of green tea catechins on the pro-inflammatory response after haemorrhage/resuscitation in rats. Br J Nutr 105: 1791-1797, 2011.

48. Johansson AS and Palmblad J: Ethyl pyruvate modulates adhesive and secretory reactions in human lung epithelial cells. Life Sci 84: 805-809, 2009. 